\title{
Corpo, subjetividade e o discurso da saúde: ensaio para profissionais de campo
}

\author{
Body, subjectivity and health discourse: an essay for field professionals
}

Cuerpo, subjetividad y el discurso de la salud: ensayos para profesionales de campo

\author{
JOSIANE CRISTINA BOCCHI \\ Universidade Estadual Paulista “Júlio de Mesquita Filho”, UNESP, Bauru-SP, Brasil
}

\begin{abstract}
RESUMO
As narrativas estéticas estão presentes nas práticas de saúde e são acompanhadas pela ênfase na alimentação saudável e na qualidade de vida. Mas se somos levados a consumir formas de vida saudável, por que tantas pessoas se sentem cada vez mais doentes? Este ensaio discute a produção desse discurso no campo da saúde e os impactos das noções de saúde e de alimentação na subjetividade atual. A saúde torna-se sinônimo de prevenção, longevidade e boa forma. Ela tem sido usada como categoria de normatividade social. Existem relações de poder inerentes a essa concepção de saúde, que geram uma hipocondria na relação entre representações de saúde e de doença. Consequentemente, temos uma medicalização dos corpos e possível reedição de um higienismo, autorizado pelo saber das especialidades médicas. Tudo em nome da boa saúde.
\end{abstract}

Palavras-chave: Saúde. Corpo. Subjetividade. Alimentação Saudável.

\begin{abstract}
Aesthetic narratives are present in health practices and are accompanied by an emphasis on healthy eating and quality of life. But if we are driven to consume healthy ways of living, why do so many people feel increasingly sick? This essay discusses the production of this discourse in the field of health and the impacts of notions of health and food on current subjectivity. Health becomes synonymous with prevention, longevity and fitness. It has been used as a category of social normativity. There are power relations inherent to this concept of health, which generate hypochondria in the relationship between representations of health and illness. Consequently, we have a medicalization of bodies and a possible reissue of hygienism, authorized by the knowledge of medical specialties. All in the name of good health.
\end{abstract}

Keywords: Health. Body. Subjectivity. Healthy Eating.

\section{RESUMEN}

Las narrativas estéticas están presentes en las prácticas de salud y vienen acompañadas por el énfasis en la alimentación saludable y en la calidad de vida. Pero si somos inducidos a consumir formas de vida saludable, ¿por qué tanta gente se siente cada vez más enferma? Este ensayo discute la producción de ese discurso en el campo de la salud y los impactos de las nociones de salud y de alimentación en la subjetividad actual. La salud se torna sinónimo de prevención, longevidad y buena forma. Esta ha sido usada como categoría de normatividad social. Existen relaciones de poder inherentes a esa concepción de salud, que generan una hipocondría en la relación entre representaciones de salud y de enfermedad. Consecuentemente, tenemos una medicalización de los cuerpos y posible reedición de un higienismo, autorizado por el saber de las especialidades médicas. Todo en nombre de la buena salud.

Palabras clave: Salud. Cuerpo. Subjetividad. Alimentación Saludable.

\footnotetext{
${ }^{1}$ Mestre em Psicologia e Doutora em Filosofia. Professora do Departamento de Psicologia da Faculdade de Ciências e do Programa de Pós-Graduação em Educação Sexual da UNESP Bauru. E-mail: josiane.bocchi@unesp.br. ORCID: https://orcid.org/0000-0002-2657-9490.
} 


\title{
UM ENSAIO E A EXPLORAÇÃO DO SEU PROBLEMA
}

As sociedades possuem códigos sobre a alimentação e o ato de comer, como aquilo que se deve comer, o que beber, o que harmoniza com tal comida e o melhor modo de fazê-lo. Segundo Claude Fischler, em entrevista cedida à Mirian Goldenberg (2011): “[...] comer não é uma forma comum de consumo, é mais do que isso. É diferente, porque o que você come se torna parte de você" (p. 229). Além disso, colocamos para dentro do corpo as propriedades de determinados alimentos, e nos refletimos a partir desse objeto (a comida, o alimento). Fischler ressalta que há uma produção de direcionamentos e regras para as pessoas seguirem quanto à alimentação, o que acaba gerando, em alguns, um sentimento de incompetência ou confusão:

\begin{abstract}
As pessoas, quando entrevistadas, estavam claramente começando a dizer que estavam confusas porque liam revistas, e elas diziam uma coisa, primeiro que não se devia comer pão, depois diziam que pão é bom; que não se devia comer muita gordura, depois que existe gordura boa e gordura má (GOLDENBERG, 2011, p. 228).
\end{abstract}

Assim, parece exagerada a produção de recomendações e prescrições sobre a alimentação, horários das refeições, como e com quem comer; e algumas vezes tais orientações parecerem contraditórias. Além de incoerências aparentemente burlescas e a confusão apontada pelo autor, é preciso sublinhar que a ênfase na alimentação e em estratégias sobre como ser saudável não tem um efeito apenas retórico, de modo que, atualmente, quando nos dedicamos a outras coisas em detrimento de monitorar ou vigiar o nosso corpo, isso soa como algo imediatamente suspeito (CHOLLET, 2018). Este cultivo à forma corporal reflete ideais contemporâneos de corpo e, segundo Feitosa Filho (2014), são os "novos cuidados de si" que se expressam "[...] pelo culto à beleza, juventude do corpo e pela ideia de que este pode ser remodelado de acordo com o desejo de cada um" (p. 163). Este autor lembra também que o século XX foi aquele que intensificou a visibilidade e as técnicas de intervenção sobre o corpo, aliado a um sentido de competição e autodisciplina (FEITOSA FILHO, 2014).

Todavia, o fenômeno de uma replicação excessiva das ideias sobre como se comportar para ter uma vida mais saudável culmina em formas de ansiedade sobre a saúde, preocupações sobre o corpo, sua aparência e seu funcionamento interno, o que pode levar a sintomas e sofrimento vivido no plano corporal. Por outro lado, tal produção discursiva interfere na autonomia das pessoas quanto às suas escolhas, pois ela está associada a um conjunto de informações que direciona comportamentos sobre o ato de comer e como ser saudável, como demonstramos em um trabalho recente, através da articulação entre a alimentação saudável, anomia social e hipocondria (BOCCHI, 2020). Com efeito, também parece haver uma proliferação de narrativas dietéticas de teor normativo nas práticas do campo da saúde e um movimento que induz ao controle alimentar saudável e à busca por um corpo funcional. Em outros termos, esse corpo idealizado que "[...] antes de ser belo, deve ser sinônimo de não gordo, saudável (em oposição ao corpo portador de algum distúrbio patológico), submetido voluntariamente a exercícios, medicamentos, tratamentos e até mesmo incisões cirúrgicas radicais" (FONTES, 2006, p. 128, grifo nosso).

A discussão sobre os ideais contemporâneos de corpo e seu vínculo com a produção do sofrimento psíquico já está presente na literatura de extração psicanalítica e sociológica, como em Fernandes (2006; 2012) e Feitosa Filho (2014), como uma resposta dos sujeitos ao chamado mal-estar na cultura. Encontramos outros trabalhos historiográficos sobre a alimentação e que reconhecem o estreitamento do seu elo com a 
área da saúde, associadas à indústria cultural de massa, como os excelentes ensaios de Nascimento (2007) e Kramer e colaboradores (2014). Este último discute o discurso da alimentação saudável sob a ótica foucaultiana do biopoder.

O presente ensaio, por sua vez, vai discutir a ascensão de um certo discurso sobre saúde e indicar algumas consequências de sua aplicação ao campo social, no que diz respeito a processos de subjetivação que incidem sobre o corpo e que merecem a atenção de profissionais das áreas de educação e saúde. Pretendemos avançar em relação ao já referido trabalho anterior, Bocchi (2020), que abriu a temática da captação do corpo saudável, sob o prisma da anomia e da hipocondria, na medida em que focaremos a seguridade em saúde e os riscos da medicalização. Nosso atual trabalho também se diferencia dos demais trabalhos da literatura supracitados, por propor uma problematização do discurso sobre ser saudável e sua relação com a dimensão política da gestão de riscos e sua análise última por uma categoria clínica.

\section{A GESTÃo DA SAÚDE E SEUS TERMOS: SAFE HEALTH}

A perspectiva da administração ou da gestão do risco emerge como noção paradigmática no campo das Ciências da Saúde e encontra-se materializada na cultura da prevenção e da seguridade. Esta é uma concepção bastante presente na racionalidade do modelo biomédico e vem se apresentando de diferentes modos na vida social; sobretudo, na constante produção de enunciados sobre o corpo e a alimentação, uma espécie de liturgia do estilo de vida saudável. Enquanto a doença é entendida como um desvio perturbador em relação à norma, a noção contemporânea de saúde caminha largamente para se tornar sinônimo de prevenção e capacidade de manter-se em forma, para obter bons desempenhos, seja no trabalho, no lazer, no amor, em diversos setores da vida comum.

Visto desse ângulo, não soa tão ruim e parece inevitável não constatar um tal movimento de naturalização inerente ao campo da saúde. Até mesmo pode parecer um contrassenso questionar fatos de saúde e fatos de doença ou parâmetros do organismo que parecem auto evidentes. A Medicina hoje é baseada em evidências, embora não seja nenhuma novidade que esta Medicina também é herdeira da tradição cientificista moderna, na qual o não mensurável é irrelevante, não obstante as qualidades intrínsecas do objeto. Perguntamos quais são os desdobramentos de tal concepção de saúde e dos sentidos, atos e efeitos do que gira em torno do discurso do saudável.

De saída, alertamos que não se trata de desconsiderar os progressivos esforços no avanço do conhecimento acadêmico-científico e nem de refutar o benefício real das novas tecnologias sobre a saúde. Primeiro, parece central nessa questão compreender que o discurso médico-científico circula como verdade estabelecida, fomentadora de uma técnica e de uma ética de cuidados, porém ele não é isento de tendências teóricas, distorções morais, concepções jurídicas e ideológicas. De modo geral, a ciência não reflete o mundo em estado "natural" - o mundo que esteve desde sempre ali - ela reconstrói o mundo da natureza e o mundo da vida, produzindo efeitos de verdade. Em segundo lugar, algumas relações sociais e políticas são construídas a partir de concepções biomédicas sobre a vida e a legitimação de práticas normativas no campo da saúde, que nos dizem como gerir cuidados básicos com o corpo, onde fumar, como dormir etc. Além de incentivar à prática exercícios físicos regulares e à realização de exames periódicos, esse conjunto de saberes e práticas ligado ao discurso médico nos incita a tomar medicamentos, mesmo quando estamos saudáveis. A formulação de um saber médico-administrativo opera como técnica geral de saúde preventiva, com 
medidas interventivas disseminadas em um regime de regras que não são impostas à força, porém estão claramente atreladas ao convencimento racional de um conhecimento produzido.

A produção do discurso contemporâneo sobre a saúde está assentada em uma razão médica ou diagnóstica. Esta concebe a cura como o restabelecimento do estado normal e atribui à noção de saudável um conceito normativo abstrato, muitas vezes idealizado e inalcançável. Ressalta-se que tal conceito de saúde também não está desvinculado de estruturas de regulação e administração da nossa vida; nesse sentido, trata-se também de um conceito politizado.

Desde o século XIX, com o movimento do higienismo, existe um entrelaçamento entre discurso sobre saúde, medicina social e razão moral, subjacente às representações sobre saúde e doença. De tal modo que, na atualidade, nos soa aceitável a ideia de que aquele indivíduo que adoece repentinamente ou morre de forma prematura, não se cuidou e foi negligente com sua saúde. Ora, na medida em que somos incentivados à permanente atitude de vigilância e atenção à saúde e à busca do bem-estar, a percepção da doença é um fenômeno cada vez mais presentificado. Na lógica do risco, estamos todos virtualmente doentes, desde antes do nascimento até a morte. Um dos efeitos dessa crença é, obviamente, a crescente medicalização do corpo de homens, de mulheres e de crianças. Essa cultura da prevenção e da seguridade contra riscos transmite a ideia de que temos o dever de nos precavermos contra doenças e outros infortúnios que rondam a perfeita saúde, como se pudéssemos realmente controlar, através de nossas escolhas e comportamentos, vetores biológicos e vitais tão fundamentais. Derivado desse raciocínio, temos, então, que nos responsabilizar não apenas pelos hábitos que poderiam levar à doença, mas também pela preocupação constante com a produção da própria saúde. Eis uma crença que esboça uma marca neoliberal dos tempos atuais, pois anuncia um tipo de responsabilização que recai unicamente sobre o indivíduo. Entretanto, é preciso lembrá-los que "[...] a possibilidade de comer saudavelmente e fazer exercício, antes de ser uma questão de escolha pessoal, depende da condição socioeconômica dos indivíduos" (CHOLLET, 2018, p. 161, tradução nossa).

E como toda proposição discursiva tem implicações, tal fenômeno se conforma a demandas de consumo das subjetividades do nosso tempo, quais sejam, as pessoas pedem por segurança, garantias, esperança e sentido. Sendo assim, o repertório do novo saudável se traduz pela constante busca por efeitos securitários. Sim, existem os suplementos, vitaminas, antioxidantes, alimentos funcionais, planos de saúde, seguro de vida, exames preventivos. Não por acaso, vivemos época das autoprescrições, um fenômeno faz parte da expansão da razão médica, e dentre alguns efeitos máximos temos

[...] a hipermedicalização por especialistas, a automedicalização, a medicalização por não especialistas, os compromissos entre estratégias de medicação (alopáticas, homeopáticas, fitoterápicas etc.), a psicopatologização das formas de vida (infância, terceira idade, adolescência, primeira infância) (DUNKER; KYRILLOS NETO, 2010, p. 430).

Num artigo intitulado Post-Scriptum sobre as Sociedades de Controle, o filósofo Gilles Deleuze (2000) indicava alguns aspectos que distinguiam uma sociedade disciplinar, como emerge na leitura de Michel Foucault, de uma sociedade de controle. Deleuze diz que algo novo está se dando: 
No regime dos hospitais: a nova medicina 'sem médicos nem doentes', que resgata doentes potenciais e sujeitos a riscos, que de modo algum demonstra um progresso em direção à individuação, como se diz, mas substitui o corpo individual e numérico pela cifra de uma matéria 'dividual' a ser controlada (DELEUZE, 2000, p. 04).

Vale a pena destacar que as sociedades disciplinares correspondem ao período do século XVIII até a Segunda Grande Guerra, seguido por seu declínio e pela respectiva ascensão da sociedade de controle. Segundo Deleuze, a clausura foi a operação fundamental da sociedade disciplinar, com a repartição do espaço em instituições fechadas (escolas, manicômios, hospitais, indústrias, prisão...), e sua ordenação no tempo de trabalho. Ele chamou esses processos de moldagem, um molde fixo e definido poderia ser aplicado às mais diversas formas sociais. A sociedade de controle, por sua vez, vigente até os dias atuais, é marcada pela interpenetração dos espaços, pela ausência de limites definidos (o outro lado da ideia de rede) e pela instauração de um tempo contínuo, no qual as pessoas não conseguem terminar coisa nenhuma, pois estão sempre enredadas numa formação permanente, de dívida impagável, prisioneiros em campo aberto. O que haveria aqui, segundo Deleuze (2000), seriam formas de modulação constante que regulam as malhas do tecido social.

Tendo esse contexto como pano de fundo de nossas preocupações, este trabalho sugere o uso noção de saúde como uma possível categoria de normatividade social, no sentido da produção de uma gestão, ou mesmo controle, em determinados setores da vida contemporânea, como a nutrição, a estética corporal e a saúde do ponto de vista biomédico, cujos procedimentos incidem diretamente sobre os sujeitos e a realidade de seus corpos. Do ponto de vista do endereçamento do tema central aqui abordado, qual seja, de elaborar uma proposta mais reflexiva sobre o manejo social das representações sobre corpo e saúde, e possíveis articulações com formas de subjetividade atual, a seção seguinte visa alcançar mais diretamente os profissionais de campo. Aqueles que atuam de forma mais imediata com a saúde e os processos educativos que dizem respeito ao corpo, como na área da Educação sexual, Educação física, Pedagogia, Psicologia, por exemplo, e mesmo em sentido amplo, aos professores, nutricionistas, fisioterapeutas, psicólogos e médicos.

\section{O CORPO COMO UM LUGAR SOCIAL: MOVIMENTO E SENTIDO}

O primeiro procedimento para indagar sobre os impactos do uso das noções de saúde e de alimentação na subjetividade contemporânea é ampliar uma compreensão da noção de corpo. O corpo não é pensado, neste trabalho, como o corpo humano e sua unidade anatomo-fisiológica e nem apenas o corpo como ordem motora adaptável a regimes de estímulos e treinamentos físicos. Para além do corpo como organismo e movimento, interessa tomar o corpo como uma categoria da experiência e da intersubjetividade. Mas para os educadores que atuam no campo da Educação ou da Saúde e outros profissionais destes campos, corpo é todas aquelas instâncias mencionadas - organismo, motricidade, anatomia etc. -, mas ele não é apenas isso, o corpo também é corporeidade. É neste sentido que propomos pensá-lo como uma categoria da experiência intersubjetiva.

A concepção do corpo como uma construção existencial e afetiva, dito de outro modo, como um ser corpóreo, pode ser encontrada a partir das significativas contribuições da fenomenologia de Maurice Merleau-Ponty para as Ciências da Vida, Ciências da Saúde e do Esporte em especial. Em Fenomenologia da percepção, 
Merleau-Ponty discute uma patologia motora a partir do caso Schneider, descrito pelo neurologista Kurt Goldstein, “[...] todas as 'funções' no homem, da sexualidade à motricidade e à inteligência, são rigorosamente solidárias" (MERLEAU-PONTY, 2011, p. 235). Merleau-Ponty usa o caso Schn., no capítulo "A espacialidade do corpo próprio e a motricidade", para discutir a relação de sentido entre corpo, ordem motora e espacialidade. Só existe espaço, porque existe um corpo que é o nosso. Não existe exterioridade, nem anterioridade entre um e outro, tampouco uma relação mecânica e objetiva: "[...] esses esclarecimentos nos permitem compreender sem equívoco a motricidade enquanto intencionalidade original. Originariamente, a consciência não é um 'eu penso', mas um 'eu posso'” (MERLEAU-PONTY, 2011, p. 192). A compreensão da noção de corpo próprio, em sua ontologia, está associada, dentre outros aspectos, ao fato do corpo ser "[...] ao mesmo tempo objeto para o outro e sujeito para mim" (MERLEAU-PONTY, 2011, p. 231). O conhecimento da dimensão da corporeidade e da percepção, como um gesto originariamente portador de sentido, é fundamental para os profissionais que exercem atividades ligadas à realidade corporal.

A psicanálise, por sua vez, não desenvolve uma noção de corporeidade exatamente. O corpo, neste referencial, estrutura-se como uma fonte da pulsão sexual e da pulsão de morte, é originariamente do corpo que partem os impulsos e as excitações do sujeito em direção ao mundo externo (ao outro em especial), mas, ao mesmo tempo, o corpo é um dos destinos da satisfação pulsional. Ainda do ponto de vista psicanalítico, o corpo é pensado como um lugar privilegiado do qual se vivencia a emergência de um excesso, através dos fenômenos da libido e sua responsividade a outros processos psíquicos, somáticos e a incidências sociais. Assim, o corpo pode interpelar e ser interpelado (pelo outro, pela cultura, por si mesmo), já que é através dele que falamos ou silenciamos, porém, ao mesmo tempo, o corpo é passível de exprimir formas de sofrimento não apenas individuais: "As práticas e os usos atuais do corpo são testemunhas de uma inegável sutilização das formas de poder, as quais definem novas modalidades de sofrimento social" (CARRENHO et al., 2018, p. 81).

Na perspectiva psicanalítica, o corpo também é sujeito e objeto ao mesmo tempo. A esse respeito, encontramos um Freud que define, em $O$ ego e o id (FREUD, 2007), a superfície corporal como uma fonte de percepção (interna e externa) para a psicogênese do ego. Ou ainda, como respaldado na teoria freudiana do narcisismo, existe uma circulação entre libido narcísica (concentrada no ego) e libido objetal, cedida ao campo dos objetos externos e que pode retornar ao ego pela via do narcisismo secundário (FREUD, 2004). Por tais razões, uma leitura psicanalítica do corpo deve considerá-lo como sexuado, social e essencialmente relacional. A propósito, existe uma intersecção entre a economia libidinal e as estruturas sociais (e econômicas). Estas últimas estão representadas nos discursos sobre a saúde, a alimentação e o corpo funcional. No entanto, uma correlação mais ampla entre estas duas economias (a psíquica e a da ordem social) não será desenvolvida no presente ensaio, mas pode ser encontrada em outros trabalhos como Safatle (2016), via discussão política dos afetos e do individualismo predicativo; em Campos, Menezes e Bocchi (2020), sobre o desamparo e a queda dos ideais que impactam o corpo e a saúde do trabalhador, e em Dunker (2021) na problematização do neoliberalismo nos contextos das políticas de sofrimento.

No presente trabalho, indicamos a relação entre o aumento da força do discurso sobre a saúde e o aumento dos diagnósticos de distúrbios alimentares, a compulsão por exercícios físicos na ausência do acompanhamento por educadores físicos e toda uma ordem de preocupações excessivas com a forma física e o controle de parâmetros corporais, o que tem gerado muito sofrimento para as pessoas. 
Nas últimas duas décadas do século XX, gradualmente, as áreas da Saúde, da Nutrição e Ciências do esporte e Exercício físico têm servido de suporte para os ideais contemporâneos de perfeição e de sucesso, encarnados na beleza e na boa forma, massivamente disseminados pela nossa época como objetos privilegiados dos processos de subjetivação, pela via do empreendedorismo. Esse último e a administração social são características da forma neoliberal de vida. O problema é que, em algum momento, eles são interiorizados como norma universal das condutas (DARDOT; LAVAL, 2016). Nesse sentido, a influência e a valorização dos setores de saber anteriormente mencionados recaem diretamente sobre o corpo e a alimentação e, assim, geram alguns derivativos semânticos como "corpo funcional", "alimentação funcional" e contribuem para a construção da ideia de um hiper corpo e da possibilidade de impulsionar um ativismo a partir desse corpo. Trata-se do corpo sempre disposto à ação. Curiosamente, na ordem neoliberal, trabalha-se o corpo para transformá-lo em um corpo-neosujeito, sempre apto ao trabalho e a regimes de trabalho cada vez mais descontínuos e intermitentes, para os quais exige-se muito mais esforço de adaptação física.

Nesse sentido, o corpo, como lugar social e subjetivo, é perfeitamente passível de tornar-se alvo de artilharia de uma genuína psicossociologia neoliberal (BOCCHI, 2020). Assim, aqueles setores da Saúde, Nutrição etc., invariavelmente, também corporificam a ascensão de narrativas administrativas e reguladoras, através dos seus domínios específicos da produção do saber. Com efeito, as informações que reforçam a importância dos alimentos funcionais, assim como a escolha de opções mais "seguras" para manter a saúde, e também um corpo funcional, estão legitimamente autorizadas pelo discurso biomédico e de outras especialidades clínicas, pois contam com o apoio e os relatos dos profissionais nutricionistas, educadores físicos, médicos e psicólogos.

No entanto, gostaríamos de pontuar que a ênfase nesse atual discurso da saúde está intrinsecamente associada a uma concepção globalizada e neoliberal de saúde física e mental a um só termo, como um índice normativo de qualidade de vida e garantia de sucesso, em enunciados como: "Você vai unir a felicidade de voltar a sentir o jeans folgado e a tranquilidade de manter o coração saudável" (REVISTA BOA FORMA, 2017, p. 65). Esse dado foi extraído de uma pesquisa qualitativa anterior que investigou a produção discursiva sobre alimentação na Revista "Boa Forma" e na Revista "Saúde", entre 2016 e $2017^{2}$. Tais dados também mostraram o emprego explícito de estratégias de marketing ("a última novidade", "Não fique de fora") e prescrições mais impositivas, como "Faça", "Planeje".

Todavia, "[...] os esforços repetidos de sacrificar o corpo, os quais se tornam afirmações repetidas dele, também são esforços para defendê-lo contra tudo que o 'arrisca"' (BUTLER, 2018, p. 61). Assim, o corpo parece revidar diante da proliferação de discursos sobre ser saudável, afirmando-se através de novas formas de ansiedade, exprimidas pela adesão a dietas radicais, pela obsessão generalizada com a perda ou ganho de peso (os quadros psicopatológicos de anorexia, bulimia são os exemplos hiperbólicos) ou através da incansável busca pelo corpo definido em regimes de exercícios físicos excessivos, assim como na busca por cirurgias estéticas e pelo uso de técnicas cirúrgicas para o controle do peso corporal.

Questionamos o quanto a produção dessas formas contemporâneas de sofrimento, assim como suas implicações são indissociáveis de um determinado horizonte de valores socioculturais e de modalidades de consumo, inclusive esta: uma vida mais saudável. E pelo discurso capitalista contemporâneo, não se consome apenas bens e produtos, mas trata-se de ofertar e fazer consumir, sub-repticiamente, formas de usufruir

\footnotetext{
2 Trata-se da iniciação científica não publicada, de Tatiana Petroni Laurito Terruggi, sob minha
} orientação, realizada na Faculdade de Ciências da UNESP-Bauru, Departamento de Psicologia. 
do seu tempo livre, de vivenciar a experiência do seu próprio corpo e, voilà, ofertar formas de ser saudável, de adoecer e de se tratar. Para isso contribuem a repetição de anúncios devotados ao marketing sobre o corpo e a saúde, replicados também nas mídias como youtube e redes sociais, que se tornaram espaços publicitários virtuais para ofertas e prescrições referentes à composição de imagens de si, no sentido do que é desejável conformar e gerir.

A construção dos padrões estéticos e comportamentais, ligados a regimes tácitos de representações identitárias, através da circulação de imagens de corpos atraentes, está na origem de fenômenos que interferem na economia libidinal dos sujeitos e nos processos psicológicos de produção de novas identidades. Isso pode gerar formas severas de sofrimento para alguns, como vimos, e um campo normalizador de condutas a partir de um ideário sócio regulador preestabelecido. E como veremos, agora, também ofertam a sua suposta solução.

Nossa hipótese é de que o medo de adoecer é indireta e intencionalmente divulgado quando se fala, de forma repetida, sobre a boa saúde e formas de produzi-la. Em nome do remédio e das boas prescrições - "Coma bem, exercite-se, viva melhor!" um modus contemporâneo de adoecer é silenciosamente estimulado. No atual momento da nossa história, em que tanto ouvimos falar em saúde, um fenômeno social e clínico chama nossa atenção: muitas pessoas estão angustiadas com relação à sua saúde ou mesmo sentem-se doentes. Assim, um dos principais resultados, deste trabalho, é pensar a correlação deste panorama de estrutura de sofrimento que se manifesta em sintomas corporais (formas de dor crônica, nas somatizações recorrentes) à produção de subjetividades conformadas às demandas do discurso capitalista, massivo e consumista.

Por esta via, trata-se de oferecer modelos individualizados, e individualizantes, de doença médica e de transtorno mental, mas que, na realidade material da vida, estendem-se a grandes seguimentos econômicos e certas populações, uma vez que parece estar em jogo a afirmação de consensos normativos e padrões supostamente mais depurados pela ciência médica com relação à saúde. Contudo, a noção de ideal de saúde é potencialmente perigosa, nos remete a estratégias medicalizantes de gestão dos processos subjetivos na atualidade e anunciam o risco da disseminação de assepsias e controles endêmicos, similares à reedição de formas de higienismo social, através da legitimação de agências estatais e da autorização do saber das especialidades clínicas do vasto campo da saúde.

Sobre o problema da medicalização, o sociólogo francês Alain Ehrenberg (2009) comenta o destaque social alcançado pelas neurociências desde a década de 1990, conhecida como a década do cérebro. As razões do sucesso das ciências neurais não têm, necessariamente, a ver com seus resultados científicos, mas sim com o estilo de resposta aos problemas do ideário social da autonomia e individuação exacerbadas. Em outras palavras, neuroprogramação e congêneres oferecem consolo para as ruínas da sociedade disciplinar, aquela que Deleuze (2000) localizou na primeira metade do século XX. Mais ainda: “[...] a maioria de nós possui uma idéia muito vaga daquilo que é científico e daquilo que não o é. Então, é perfeitamente possível se apoiar sobre a biologia em casos para os quais ela não é apropriada" (EHRENBERG, 2009, p. 201).

Todavia, quanto mais se lê sobre si - como na veiculação de testes de personalidade, sua banalização nas redes sociais e as psicologias contribuem para isso aqui - e quanto mais se lê sobre seus estados corporais saudáveis ou mórbidos, menos se sabe realmente sobre eles e afasta-se de uma experiência de cuidado, a qual poderia ser vivida de forma mais autêntica. Segundo David Le Breton (2007), haveria um risco presente na experiência corporal, pela proximidade entre uma sociologia do corpo e as demais sociologias "[...] aplicadas à saúde, à doença, à interação, à sexualidade, à 
alimentação, às atividades físicas e esportivas, etc. O risco é a diluição do objeto, insuficientemente definido pelo pesquisador" (LE BRETON, 2007, p. 36), que na ânsia de abarcar tudo, perde seu objeto.

A fixação nesses ideais contemporâneos de corpo e naquilo que o corpo ingere (alimentos orgânicos, suplementos, vitaminas) revelam modos emergentes de subjetivação. E através dos dispositivos de discursos biomédico, midiático e cultural sobre a saúde, inscreve-se uma noção de saúde reduzida à ideia de prevenção de riscos e de obter um corpo apto, também como já concluímos em Bocchi (2020).

Mas não se trata de pensar em bloco e nem vamos jogar tudo fora. Para os profissionais da saúde e educadores em geral, é necessário discriminar que o problema não é a prática de esportes, o exercício físico regular ou o anseio por hábitos de vida mais saudáveis em si mesmos. É imprescindível reconhecer os benefícios que tais práticas de cuidado de si têm para a saúde física e mental. No entanto, é necessário estarmos vigilantes para aquilo que é transmitido como "padrão-ouro" em saúde, mas que, na verdade, é um simulacro de marcos regulatórios de tipos sociais, disfarçados de promessas de bem-estar e de transcendência do eu. Outrossim, de forma subjacente, quanto aos discursos que incitam aos mais aprimorados hábitos saudáveis, é necessário que os profissionais de campo estejam conscientizados dos problemas que aquela normatização envolve, como uma política de medicalização dos corpos.

\section{O SAUDÁVEL E O MORIBUNDO ENTRELAÇADOS}

Um aspecto central para os profissionais da saúde e da educação é não se esquecerem do âmbito do sofrimento social gerado pela mercantilização da forma corporal. Esse problema não pode continuar sendo evitado como um ponto cego das nossas intervenções: plenamente saudáveis ou permanentemente doentes? A normalidade em saúde parece ter sido substituída pelas noções de prevenção e de desempenho produtivo. Se nossos ancestrais diziam que prevenir era o melhor remédio, agora prevenir se tornou o único remédio, e não apenas no sentido figurado. A diferença é que esse sentido de prevenção envolve uma aliança com os conglomerados das indústrias química e farmacêutica, além de incorrer no que chamamos de medicalização de corpos. O atual discurso da saúde, portanto, contém estratégias psicopolíticas de apropriação de um corpo saudável e de um corpo doente, paradoxalmente imbrincados, como demonstramos em trabalho anterior sobre a hipocondria (BOCCHI, 2020). Parece que o convencimento sobre a saúde segura e preventiva, e a consequente medicalização a que referimos, só ocorre devido ao apelo ao duplo negativo da saúde: o adoecer.

A medicalização não é recente. Na história da constituição da doença mental, a Medicina apropriara-se de um objeto que antes era filosófico, como as diversas experiências clássicas da loucura, como a mania, a melancolia, a idiota, e todas se tornaram alienação do mental (PESSOTTI, 1996). A medicalização concerne a estratégias e procedimentos explicativos aplicados a fenômenos humanos, recorrendo unicamente a um sistema de identificação, nomeação e inscrição pelo saber médico e a ordenação dos fenômenos em uma categoria clínico diagnóstica, que termina por ser interpretada no contexto de uma patologia. Conforme o objeto da medicalização incida sobre grupos em processos de reivindicação por mais direitos - como gays, negros, mulheres, imigrantes - pode-se tratar de medicalização do social. As operações medicalizantes também se encontram no contexto escolar. A medicalização da infância (ou da educação) não é um fenômeno novo. Diagnostica-se cada vez mais cedo: nos anos 70 era disfunção cerebral mínima, anos 80 e anos 90 a dislexia e nos anos 2000 
seguiu-se transtorno de déficit de atenção e hiperatividade (TDAH). Essa última coincide com a escandalosa venda do Metilfenidato (Ritalina ${ }^{\circledR}$ ), em grande escala, indicado a crianças (pacientes) com uma "síndrome comportamental" caracterizada por distraibilidade, perda de atenção e labilidade emocional; aliás, categorias bastante controversas para crianças em desenvolvimento. Não vamos entrar nessa discussão agora, mas apenas indicar que a docilização das crianças e a manutenção do cenário contido entre família e escola é uma das finalidades da medicalização nesse setor.

$\mathrm{Na}$ medida em que as estratégias racionais de argumentação, empregadas pelos processos de medicalização, têm um papel imediato de acionar prescrições medicamentosas, além da produção e do consumo de diagnósticos e de psicofármacos, a medicalização culmina em modos de psicopatologização. O curioso é que essas estratégias não visam nenhuma cura, nem à elaboração das ansiedades quanto à saúde ou doença, mas buscam apenas o manejo e contenção do sujeito frente à sua passionalidade. Ademais, a categorização dos indivíduos em uma razão diagnóstica oferece a ilusão do controle de si numa lógica de autogerenciamento. Ao que tudo indica a medicalização, seja do social, da infância ou dos corpos, pela via da hipocondria, visa apenas uma regulação do que vai mal ou do não ajustado no corpo, gestão de riscos e de suas extrapolações, nada pode escapar às estruturas de poder.

A relação paradoxal entre saúde e doença, igualmente presente na captação dos corpos saudáveis e não saudáveis, pode ser elucidada através do modelo psicanalítico da hipocondria, como argumento teórico para encaminhar a conclusão de que o discurso da saúde como gestão de riscos se sustenta a partir de suas negações: a doença e o perigo.

Contrariando as aparências e o senso comum, o que caracteriza as ansiedades hipocondríacas e expectativas em relação ao corpo e seu funcionamento não é o medo de doenças, mas ter a constante convicção de "já estar" doente. Para a psicanálise, a hipocondria não é necessariamente uma patologia, mas remete a uma experiência estruturante e inconsciente de figurabilidade e de percepção dos estados corporais (VOLICH, 2015). Freud observa que a pessoa não tem o dano orgânico, mas vivencia o terror antecipatório de que eles venham a ocorrer. Freud (1996) também diz que um ataque de pânico pode vir apenas como angústia (sem conteúdos representáveis), ou vir associado ao medo de morrer, enlouquecer ou crença em um distúrbio corporal.

O retraimento hipocondríaco sobrecarrega libidinalmente a infraestrutura afetiva e erógena do corpo, pois este adquire uma intensa sensibilidade para a interioridade visceral, manifesta na inclinação do sujeito para sua propriocepção. Mas externamente, ele permanece preso a um modo "recolhido" de subjetividade, fixada no domínio corporal ainda fragmentado: "O hipocondríaco recolhe o interesse e a libido - esta última de modo especialmente nítido - dos objetos do mundo exterior e os concentra sobre o órgão do qual está se ocupando" (FREUD, 2004, p. 104). Assim, a hipocondria parece estar ligada a uma tentativa mais basal de simbolização dos conflitos psíquicos.

Dados da experiência psicoterápica, nos casos de hipocondria, constatam uma fragmentação da imagem corporal, indicada pela nomeação de partes do corpo ou órgãos que não mantêm relação entre si e não são reconhecidos pelo sujeito: era como se aquelas coisas (neurônios, ouvido, cabeça vazia) não fossem ela própria. Os órgãos permanecem como objetos parciais não simbolizados. Em alguns casos, os pacientes identificam-se à incorporação do objeto morto (na esfera da vida psíquica). Nossa paciente temia transmitir a doença Covid-19, sem qualquer indício de que ela estivesse contaminada, posto que estava em isolamento social. Curioso, mas não surpreendente, que tivesse medo de transmitir, mas não de se contaminar.

Os discursos sociais sobre prevenção e corpos saudáveis (uma saúde segura) induzem a uma inversão nos processos de unificação e de integração das experiências 
sensoriais e psíquicas que levam à aquisição da imagem corporal. Aqueles discursos parecem facilitar o contrário, uma desagregação das representações de corpo, somos incitados a voltar quase constantemente para uma vivência mais primitiva e compartimentalizada da relação com o próprio corpo. Ora, há especialidades clínicas, divididas em subespecialidades e já é conhecida a ausência de unidade no discurso médico tradicional.

Nossa suspeita é que as pressões do atual discurso do saudável alcancem uma dimensão estruturante da personalidade, evocando o medo de adoecer, a fim de modelar escolhas e comportamentos desejáveis. É preciso ficar claro que as injunções direcionadas à conquista do corpo saudável são mantidas à custa da ameaça latente da reedição psíquica da figura do moribundo, isto é, aquele que está prestes a morrer, quase morto, quase vivo. Não por acaso, nas formas de sujeição corporal, o "[...] 'estar em perigo' denota um perigo ligeiramente menos terrível do que a morte" (BUTLER, 2018, p. 61). Pelas indicações trazidas até aqui, esta nos parece ser uma das formas de regulação desse ideal da boa saúde, um safe health, por parte daqueles novos discursos.

\section{CONSIDERAÇÕES FINAIS}

A promoção desse tipo de discurso sobre a saúde, ao concentrar diversos saberes, gera um efeito paradoxal de panaceia e anomia ao mesmo tempo, ou seja, eles têm aparência de serem polivalentes, hiperpotentes, mas justamente por isso produzem estados de confusão, indeterminações e uma impressão de que próprio sujeito nada sabe sobre ele e o coexistir em seu próprio corpo. A insistência discursiva sobre a qual discorremos, neste trabalho, é um dos principais fatores sociais responsáveis pelo aumento de obsessões e distorções perceptivas quanto à forma corporal. Fenômenos os quais estão vinculados a certos tipos de sofrimento vividos de forma solitária, mas que mantêm uma ligação com o que a cultura diz sobre saúde, beleza e perfeição física. Tornou-se um lugar comum falar em ditadura da beleza e padrões elevados quanto à imagem corporal. No entanto, o que é problemático não é o padrão ele mesmo, mas sua finalidade instrumental pela via da lógica do consumo e da responsabilização do sucesso ou do fracasso no indivíduo e, agora, em um dos seus tesouros mais preciosos, seu corpo.

O modelo da hipocondria, extraído do campo da psicopatologia, como uma figura clínica mais atípica da melancolia, pode ser elucidativo no debate sobre a regulação de processos subjetivos contemporâneos e do sofrimento que leva ao consumo de remédios, de diagnósticos, de auto diagnósticos, o que, não raras vezes, leva a formas autocráticas e incapacitantes para a ação e iniciativas de transformação social. Este ensaio, por fim, sugere como resultado a noção de que as relações de poder, imanentes à concepção de prevenção de riscos em saúde, impelem a uma hipocondria na relação entre sujeito, representações de saúde e de doença. O próprio corpo e suas partes (órgãos, regiões, sistemas), objeto da queixa hipocondríaca, lembra-nos da vigilância constante em relação à angústia mórbida de decomposição, de modo não muito distante do que o atual discurso biomédico reitera ("Melhor prevenir, senão"). Tais orientações nos impelem a auscultar o quase silêncio dos órgãos, mesmo na ausência de doenças, para prevenir e fornecer dados que certificam a saúde. Porém o jugo à saúde plena só funciona à custa de sua própria negação, ou seja, a mobilização da imagem invertida da saúde - o adoecer, a dissolução que tende à morte real - que se traduz em fantasias e temores de tornar-se moribundo.

Do ponto de vista do sujeito, este oferece o próprio corpo ao campo do olhar (esse outro médico, o social). A psicanálise lembra-nos de que o corpo humano precisa ser 
afetivamente investido para se constituir em uma unidade diferenciada, enquanto que, do ponto de vista do discurso dominante em saúde, nada pode ficar de fora, tudo que tem valor capital deve ser monitorado, codificado e contabilizado. Mas o sujeito hipocondríaco parece se vingar. Se ele pergunta "Doutor, o que eu tenho?", é para em seguida dizer: "Você não sabe"! Freud, em 1893, ao atender um caso de neurastenia, naquele período um quadro próximo à hipocondria, refere que falta palavras ao paciente para descrever sua dor e frequentemente ele fica ofendido por não se sentir compreendido pelo clínico. Não é na fala do especialista que se encontra a verdade do doente.

Sugerimos que as práxis relacionadas aos setores da Saúde, Nutrição, Estética corporal, Reabilitação, levem em conta o horizonte de questões pontuadas neste ensaio. Do contrário, podem incorrer na reabilitação de um tipo de higienismo, agora revestido pelo saber autorizado das especialidades e pelo discurso de segurança da Medicina, tudo em nome da boa saúde. O papel de tais profissionais é intervir no corpo enquanto sujeito e lugar de intersubjetividade, experiência de corporeidade, alteridade e coexistência, e não intervir apenas no corpo fragmentado, enquanto anatomia ou ordem motora, mas investi-lo como um lugar social habitado, passível de fornecer resistência aos movimentos hegemônicos que certamente recaem sobre as áreas da Saúde e da Educação.

\section{REFERÊNCIAS}

BOCCHI, J. C. Anomia e hipocondria nas relações entre corpo, saúde e o sofrimento na contemporaneidade. Sofia, Vitória-ES, v. 9, n. 2, p. 188-203, dez. 2020. Disponível em: https://periodicos.ufes.br/sofia/issue/view/1238. Acesso em: 30 jan. 2021.

BUTLER, J. A vida psíquica do poder: teorias da sujeição. Tradução Rogério Bettoni. Belo Horizonte: Autêntica Editora, 2018.

CAMPOS, E. B., MENEZES, L. S., BOCCHI, J. C. A psicanálise e o desamparo frente à crise de valores e ideais na atualidade. Estudos Interdisciplinares em Psicologia Londrina, v. 11, n. 3 supl., p. 04-27, dez. 2020. Disponível em: http://www.uel.br/revistas/uel/index.php/eip/article/view/41067. Acesso em: 25 fev. 2021.

CARRENHO, A. C.; RIBEIRO, C. E.; RODRIGUES, D. S.; COPPEDÊ, D. R.; MOREIRA, L. E. V.; LIMA, R. A.; MUSSE, M. A.; SILVA JUNIOR, N.; AMBRA, P. E. S.; COSSI, R. K.; CARVALHO NETO, S.; COELHO, B. M. O corpo como lugar de sofrimento social. In: SAFATLE, V.; SILVA JUNIOR, N.; DUNKER, C. (org.). Patologias do social: arqueologias do sofrimento psíquico. Belo Horizonte: Autêntica Editora, 2018. p. 81-110.

CHOLLET, M. Beauté fatale: les nouveaux visages d'une aliénation féminine. Paris: Éditions La Découverte/Poche, 2018.

DARDOT, P.; LAVAL, C. A nova razão do mundo: ensaio sobre a sociedade neoliberal. Tradução Mariana Echalar. São Paulo: Boitempo, 2016.

DELEUZE, G. Post-scriptum sobre as sociedades de controle: in L'Autre Journal, n. 1, maio de 1990. In: DELEUZE, G. Conversações. Tradução Peter Pál Pelbart. Rio de Janeiro: Editora 34, 2000. p. 219-226.

DUNKER, C. A hipótese depressiva. In: SAFATLE, V.; SILVA JUNIOR, N.; DUNKER, C. (org.). Neoliberalismo como gestão do sofrimento psíquico. Belo Horizonte: Editora Autêntica, 2021. p. 168205.

DUNKER, C. I. L.; KYRILLOS NETO, F. Curar a homossexualidade?: a psicopatologia prática do DSM no Brasil. Revista Mal Estar e Subjetividade, Fortaleza, v. 10, n. 2, p. 425-446, jun. 2010. Disponível em: $\quad$ http://pepsic.bvsalud.org/scielo.php?script=sci arttext\&pid=S151861482010000200004\&lng=pt\&nrm=iso. Acesso em: 01 nov. 2020. 
Josiane Cristina Bocchi

EHRENBERG, A. O sujeito cerebral. Psicologia Clínica, Rio de Janeiro, v. 21, n. 1, p. 187-213, 2009. (Tradução Marianna T. de Oliveira; MonahWinograd. Texto original publicado em 2004).

FEITOSA FILHO, O. A. Um olhar psicanalítico sobre a vigorexia. Revista Subjetividades, Fortaleza, v. 14, n. $1, \quad$ p. 162-171, abr. $2014 . \quad$ Disponível em: http://pepsic.bvsalud.org/scielo.php?script=sci_arttext\&pid=S235907692014000100015\&lng=pt\&nrm=iso. Acesso em: 24 abr. 2021.

FERNANDES, M. H. O corpo e os ideais no mal-estar feminino. Revista Científica Guillermo de Ockham, Cali-Colombia, v. 10, n. 1, p. 135-140, 2012.

FERNANDES, M. H. Transtornos alimentares. São Paulo: Casa do Psicólogo, 2006.

FONTES, M. Uma leitura do culto contemporâneo ao corpo. Contemporânea, Florianópolis, v. 4, n. 1, p. 117-136, 2006.

FREUD, S. O eu e o id (1923). In: FREUD, S. Escritos sobre a psicologia do inconsciente (1923-1938). Tradução Luiz Alberto Hanns. Rio de Janeiro: Imago, 2007. p. 13-92. (Obras psicológicas de Sigmund Freud, v. 3).

FREUD, S. À guisa de introdução ao narcisismo (1914). In: FREUD, S. Escritos sobre a psicologia do inconsciente (1911-1915). Tradução Luiz Alberto Hanns. Rio de Janeiro: Imago, 2004. p. 95-131. (Obras psicológicas de Sigmund Freud, v. 1).

FREUD, S. Sobre os fundamentos para destacar da neurastenia uma síndrome específica denominada "neurose de angústia" (1895 [1894]). Tradução Abreu, J. O. A.; Oiticica, C. M. In: SALOMÃO, J. (org.). Edição standard brasileira das obras psicológicas completas de Sigmund Freud: v. 3. Rio de Janeiro: Imago, 1996. p. 93-120.

GOLDENBERG, M. "A comida como objeto de pesquisa": uma entrevista com Claude Fischler. Psicologia Clínica, Rio de Janeiro, v. 23, n. 1, p. 223-242, 2011. Disponível em: http://pepsic.bvsalud.org/scielo.php?script=sci_arttext\&pid=S010356652011000100014\&lng=pt\&nrm=iso. Acessos em: 10 dez. 2020.

KRAEMER, F. B.; PRADO, S. D.; FERREIRA, F. R.; CARVALHO, M. C. V. S. O discurso sobre a alimentação saudável como estratégia de biopoder. Physis: Revista de Saúde Coletiva, Rio de Janeiro, v. 24, n. 4, p. 1337-1360, 2014.

LE BRETON, D. A sociologia do corpo. Tradução Sônia M. S. Fuhrmann. Petrópolis: Editora Vozes, 2007.

MERLEAU-PONTY, M. Fenomenologia da percepção. Tradução Carlos Alberto Ribeiro de Moura. 4. ed. São Paulo: Editora WMF Martins Fontes, 2011. (Texto original publicado em 1945).

NASCIMENTO, A. B. Comida: prazeres, gozos e transgressões. Salvador: EDUFBA, 2007.

PESSOTTI, I. O século dos manicômios. 2. ed. Rio de Janeiro: Editora 34. 1996.

REVISTA BOA FORMA. São Paulo: Editora Abril, n. 367, maio 2017.

SAFATLE, V. O circuito dos afetos: corpos políticos, desamparo e o fim do indivíduo. Belo Horizonte: Autêntica Editora, 2016.

VOLICH, R. M. Hipocondria: impasses da alma, desafios do corpo. 3. reimp. São Paulo: Casa do Psicólogo, 2015. (Coleção: Clínica Psicanalítica).

Recebido em: 10 dez. 2020.

Aprovado em: 24 abr. 2021. 